\title{
DataStreme Ocean: Providing Pre-college Teachers Study Opportunities in Oceanography Emphasizing Internet-Delivered Data
}

\author{
Ira W. Geer \\ American Meteorological Society $\cdot$ Washington, DC USA
}

The American Meteorological Society (AMS) Education Program is combining resources with the National Oceanic and Atmospheric Administration (NOAA) to develop and nationally implement DataStreme Ocean, a content-rich and pedagogically appropriate educator enhancement oceanography course.

DataStreme Ocean is a distance-learning course for educators, that explores the world ocean and the role of the ocean in the Earth system. Special emphasis is on the flow and transformations of water and energy into and out of the ocean, the internal properties and circulation of the ocean, marine ecosystems, the role of the ocean in global climate change, interactions between the ocean and the other components of the Earth system, and the human/societal impacts on and responses to those interactions.

Learning materials include a customized text, a study guide, and a course homepage. The text serves as a reference for educators using investigations that model scientific inquiry and the development of critical thinking skills. The homepage delivers investigations created in real time and keyed to current online oceanographic data, links to ocean and ocean-related data sites, and the Weekly Ocean News (a continually updated compilation of recent ocean-related events or developments). The backbone of the course is the use of near real time data from ocean observatories to investigate the workings of the ocean. Among the 24 investigations, El Niño and La Niña are examined by educators using current data from the Tropical Atmosphere Ocean (TAO) array of buoys. Predicted and observed tides are studied via NOAA's CO-OPS. The ocean's temperature and salinity structure is tracked with Argo float profilers. And global sea surface temperature, ocean color, and sea ice extent are investigated using satellite remote sensing data.

Twenty-two, 3-member Local Implementation Teams in 18 states are pilot testing DataStreme Ocean. When fully deployed (January, 2004) the course will be offered locally through these teams. Two team members have been selected from the alumni of the Maury Project-the AMS education program's two-week educator workshop on the physical foundations of oceanography held annually at the U.S. Naval Academy. The third member is an oceanographer or local college science faculty member. The educator team leader has also received additional oceanography instruction. Teams will work with up to eight educators per term through three class meetings and weekly demonstration of study efforts with electronic interactions and telephone calls between the educatorstudent participants and their team mentors.

Educators who sign-up and complete this course are expected to apply what they learn in their classrooms. They will also work towards incorporating oceanographic topics and data from observatories across the pre-college curriculum by acting as ocean education resource persons and peer trainers in their schools and school districts. Those successfully completing DataStreme Ocean will be awarded graduate credit from the State University of New York at Brockport.

To view the pilot project's course homepage, go to: http: / / www.ametsoc.org / amsedu /DS-Ocean / home.html. Inquiries and comments can be sent to Ira W. Geer, Director, AMS Education Program (geer@dc. ametsoc.org). त्य

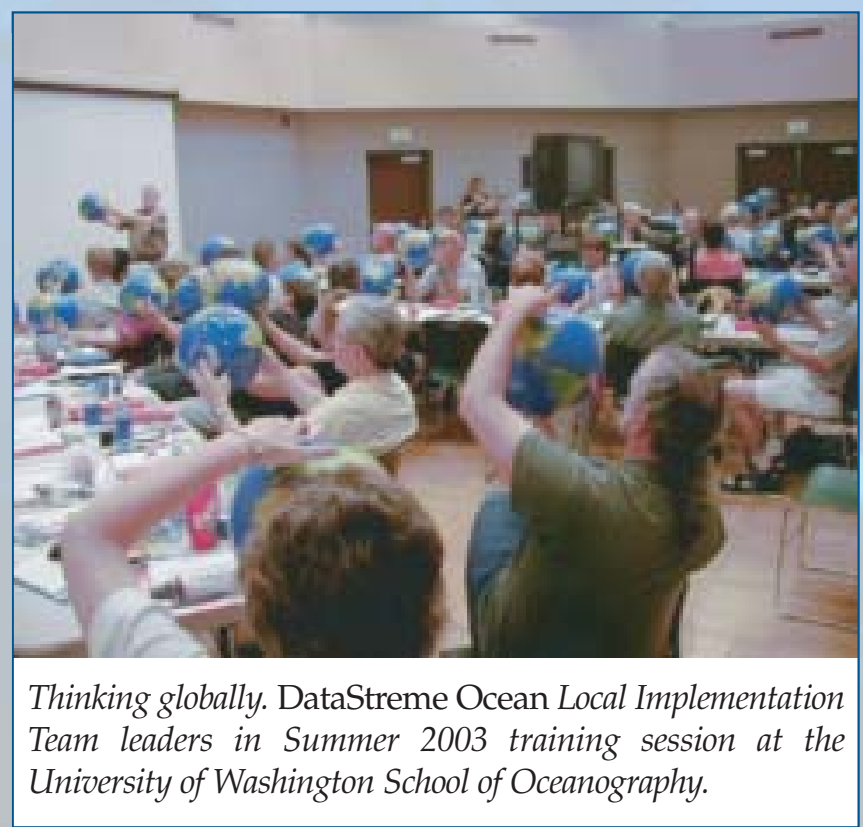



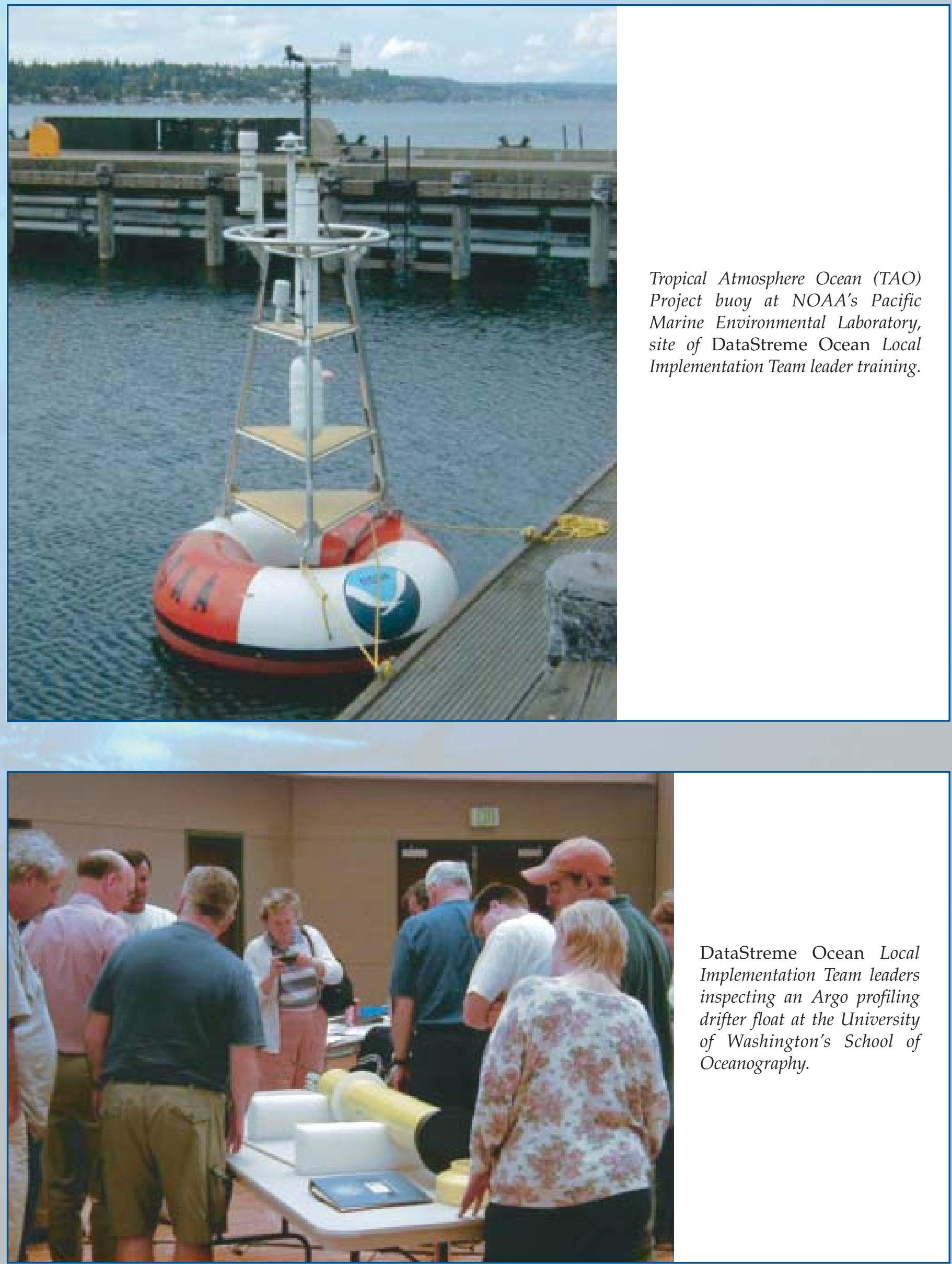